\title{
Application of Microwave Moisture Sensor for Determination of Oil Palm Fruit Ripeness
}

\author{
You Kok Yeow, Zulkifly Abbas ${ }^{1}$, Kaida Khalid ${ }^{1}$ \\ Department of Radio Communication Engineering, Faculty of Electrical Engineering, Universiti Teknologi Malaysia, \\ 81310 UTM Skudai, Malaysia, kyyou@fke.utm.my \\ ${ }^{1}$ Department of Physics, Faculty of Science, Universiti Putra Malaysia, 43400 UPM Serdang, Malaysia, za@fsas.upm.edu.my
}

\begin{abstract}
This paper describes the development of a low cost coaxial moisture sensor for the determination of moisture content (30\% to $80 \%$ wet-weight basis) of the oil palm fruits of various degree of fruit ripeness. The sensor operating between $1 \mathrm{GHz}$ and $5 \mathrm{GHz}$ was fabricated from an inexpensive $4.1 \mathrm{~mm}$ outer diameter SMA coaxial stub contact panel which is suitable for single fruit measurement. The measurement system consists of the sensor and a PC-controlled vector network analyzer (VNA). The actual moisture content was determined by standard oven drying method and compared with predicted value of fruit moisture content obtained using the studied sensor. The sensor was used to monitor fruit ripeness based on the measurement of the phase or magnitude of reflection coefficient and the dielectric measurement software was developed to control and acquire data from the VNA using Agilent VEE. This software was used to calculate the complex relative permittivity from the measured reflection coefficient between $1 \mathrm{GHz}$ and $5 \mathrm{GHz}$.
\end{abstract}

Keywords: Vector network analyzer, moisture content, reflection coefficient, oil palm fruits, microwave sensors, dielectric constant

\section{INTRODUCTION}

$\mathrm{P}$ ALM OIL has become increasingly popular as it provides rich sources of $\alpha$ and $\beta$-carotene and vitamin $E$, which play important roles in blood coagulation, suppression of cholesterol production and cancer inhibition. Nutrition as well as environment protection will have a prominent role in consumer's choice of edible oil consumption. Besides its nutritional value, it is a well-known raw material for oleo chemical industry and bio-fuel for automobiles.

Palm oil is obtained from the mesocarp of the oil palm fruits. Researchers [1], [2] found that the quality of palm oil is closely related to the moisture content $m . c$ in the fruits, as well as the fruit ripeness. When the oil palm fruit is ripening, the oil content reaches the maximum, but the moisture content $m . c$ reaches the minimum $(\sim 30 \%$ m.c $)$ in the fruit [1], [2]. Therefore, the close relationship between the moisture and oil contents in the mesocarp gives a possibility of using percentage of moisture content $m . c$ as a parameter to gauge the mesocarp ripeness and the harvesting time.

Various microwave sensors have been utilized to estimate the ripeness of oil palm fruits, such as microstrip sensor (MWG) [12], coplanar sensor (CBCPW) [13], rectangular dielectric waveguide (RDWG) [15], monopole [16] and openended rectangular waveguide (OERWG) [17] as shown in Fig.1. Microstrip and coplanar sensors based on attenuation measurement were the first to have been successfully used to estimate the amount of moisture content m.c in the oil palm fruits. Unfortunately, the sensors require laborious sample preparation as the fresh mesocarp of the oil palm fruit has to be separated from the nut and crumbled to form a semi-solid sample. The preparation of the fruit sample is very time consuming. The comparison of previous work features for oil palm fruit measurements using microwave sensors was tabulated in Tab.1.

In this study, the open-ended coaxial probe is used as a moisture sensor to determine the moisture content $m . c$ of oil palm fruits of various degrees of fruit ripeness at room temperature by using reflection techniques. Furthermore, a model is developed to describe the relation between reflection coefficient and moisture content $m . c$ of the oil palm mesocarp for frequency range $1 \mathrm{GHz}$ to $5 \mathrm{GHz}$.
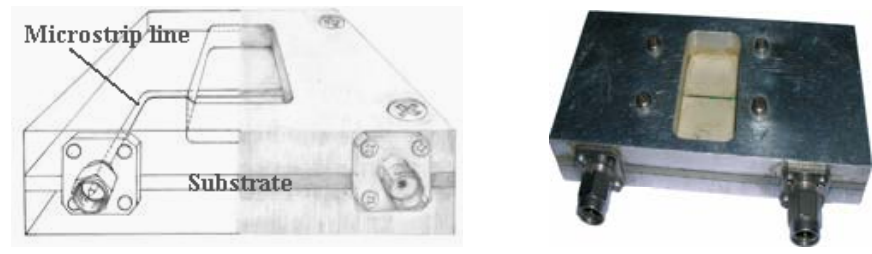

(a)
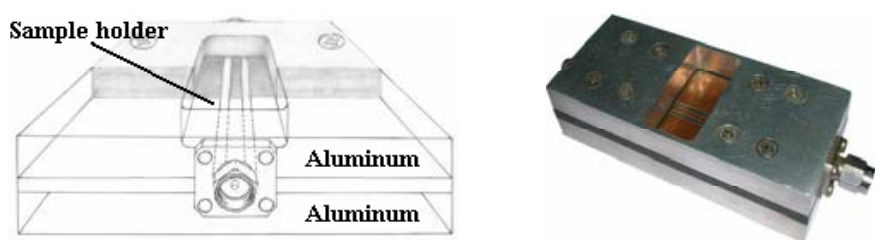

(b)

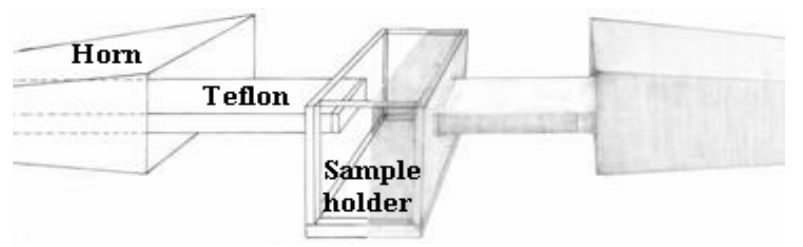

(c) 


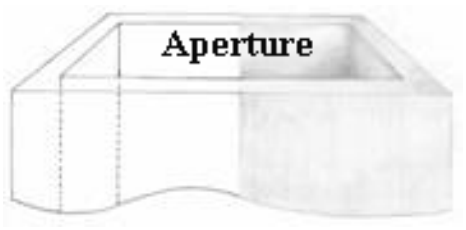

(d)

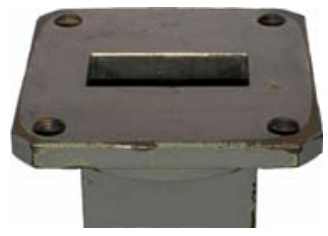

\section{EXPERIMENT AND METHODS}

Experimentation planning includes fabrication and construction of open-ended coaxial sensor, oil palm sample preparation, sensor calibration, reflection measurements and moisture content m.c measurements in this study.

\section{A. Fabrication of sensor}

The probe was fabricated from a $12.7 \mathrm{~mm}$ by $12.7 \mathrm{~mm}$ square flange, SMA stub contact panel. The stub was machined flat and polished. The diameter of the inner and outer conductors was $1.3 \mathrm{~mm}$ and $4.1 \mathrm{~mm}$, respectively. The dielectric material separating the inner and outer conductor was Teflon (PTFE), as shown in Fig.2.

\section{B. Sensor calibration}

For this measurement calibration, no loss was assumed for
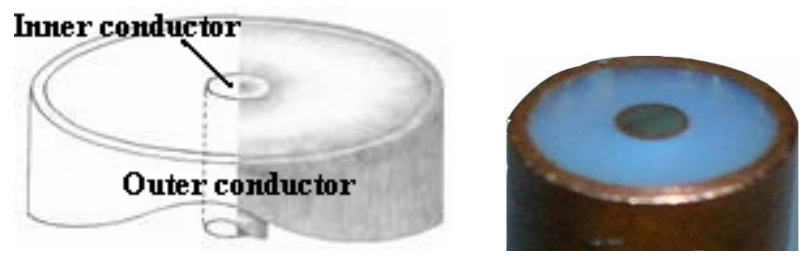

(f)

Fig.1 (a) Microstrip sensor (MWG) [12] (b) Coplanar sensor (CBCPW) [13] (c) Rectangular dielectric waveguide (RDWG) [15] (d) Rectangular waveguide (OERWG) [17] (e) Monopole [16] (f) coaxial waveguide (OECWG) (This work). the electromagnetic wave when it is transmitted in offset coaxial line (see Fig.2 (a)). Thus, the error network calibration parameters of $S_{11}$ and $S_{22}$ in Fig.2 (b) are equal to zero. Finally, the concept of Fig.2 (b) was simplified as in Fig.2 (c), where the $S_{12}$ and $S_{21}$ are replaced by transmission factor, $\exp \left(-j k_{c} d_{c}\right)$ [18].

$$
\Gamma_{\text {Actual }}=\Gamma_{A A^{\prime}} \exp \left(2 j k_{c} d_{c}\right)
$$

where $d_{c}$ and $k_{c}$ are the physical length (in meter) and propagation constant of coaxial line, respectively.

Table 1 Comparison of previous work features for oil palm fruit measurements using microwave sensors

\begin{tabular}{|c|c|c|c|c|c|c|c|c|}
\hline \multirow{2}{*}{$\begin{array}{l}\text { Type of } \\
\text { sensor }\end{array}$} & \multicolumn{8}{|c|}{ Comparison features of microwave sensor for oil palm fruits measurements } \\
\hline & $\begin{array}{l}\text { Operating } \\
\text { frequency }\end{array}$ & $\begin{array}{c}\text { Nondestructive } \\
\text { test }\end{array}$ & $\begin{array}{l}\text { Set-up } \\
\text { speed }\end{array}$ & $\begin{array}{l}\text { Cost of } \\
\text { sensor }\end{array}$ & $\begin{array}{c}\text { One-port } \\
\text { measurements }\end{array}$ & $\begin{array}{c}\text { Single fruit } \\
\text { measurements }\end{array}$ & Sensitivity & Precision \\
\hline MWG, [12] & $10.7 \mathrm{GHz}$ & No & Slow & Low & No & No & Good & Good \\
\hline СBCPW, [13] & $2.2 \mathrm{GHz}$ & No & Slow & Low & No & No & Good & Good \\
\hline $\begin{array}{c}\text { Commercial } \\
\text { HP 85070B } \\
\text { OECWG, [14] }\end{array}$ & $\begin{array}{c}0.13-20 \\
\mathrm{GHz}\end{array}$ & No & Slow & Expensive & Yes & No & Good & Good \\
\hline RDWG, [15] & $8-12 \mathrm{GHz}$ & No & Slow & Low & No & No & Good & Good \\
\hline $\begin{array}{l}\text { Monopole, } \\
\text { [16] }\end{array}$ & $0.5 \mathrm{GHz}$ & Yes & $\begin{array}{l}\text { Very } \\
\text { fast }\end{array}$ & Very low & Yes & Yes & Very good & Poor \\
\hline OERWG, [17] & $8-12 \mathrm{GHz}$ & No & Fast & Very low & Yes & No & Good & Good \\
\hline $\begin{array}{l}\text { OECWG } \\
\text { (This work) }\end{array}$ & $1-5 \mathrm{GHz}$ & Yes & $\begin{array}{l}\text { Very } \\
\text { fast }\end{array}$ & Very low & Yes & Yes & Good & Good \\
\hline
\end{tabular}




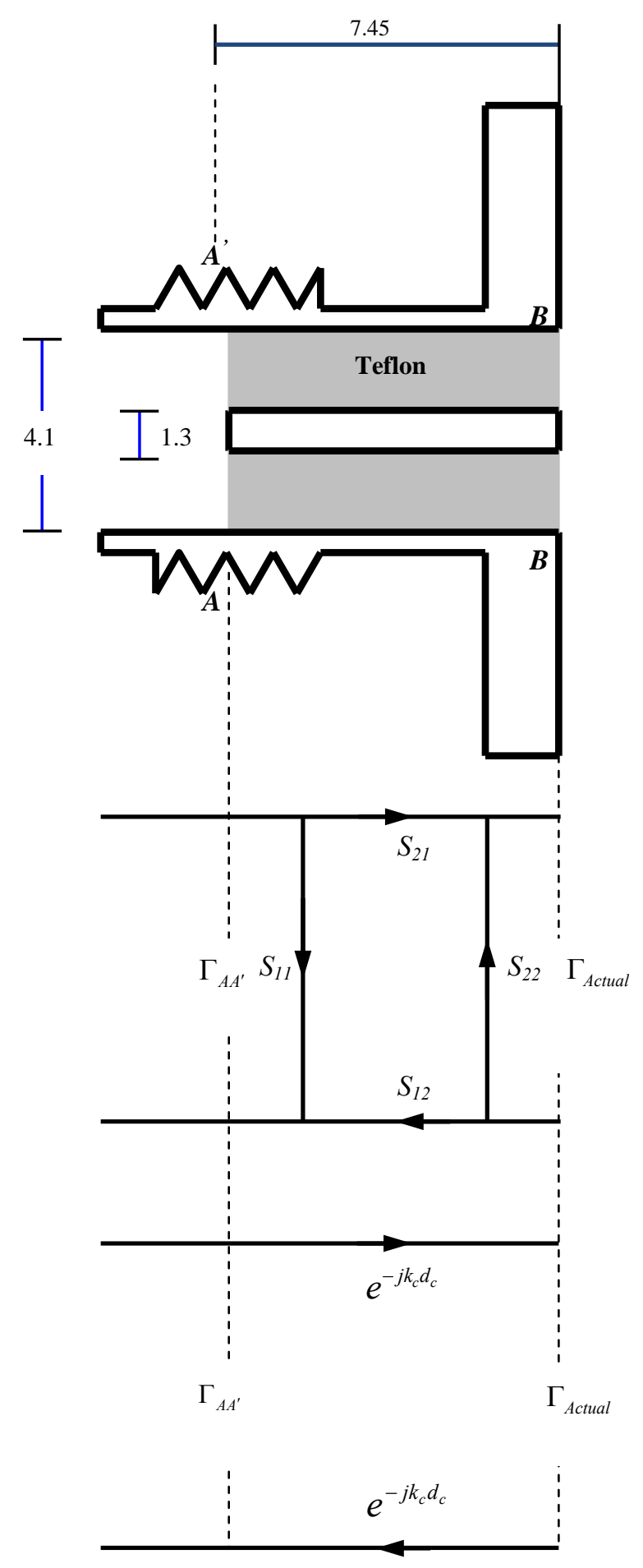

(a)

\section{Reflection measurements}

The measurement consists of a computer controlled HP 8720B vector network analyzer (VNA) that operates between $1 \mathrm{GHz}$ and $5 \mathrm{GHz}$. The moisture sensor was connected to VNA port by coaxial cable as shown in Fig.3. All reflection measurements of fruit samples were carried out at room temperature $(25 \pm 1)^{\circ} \mathrm{C}$.

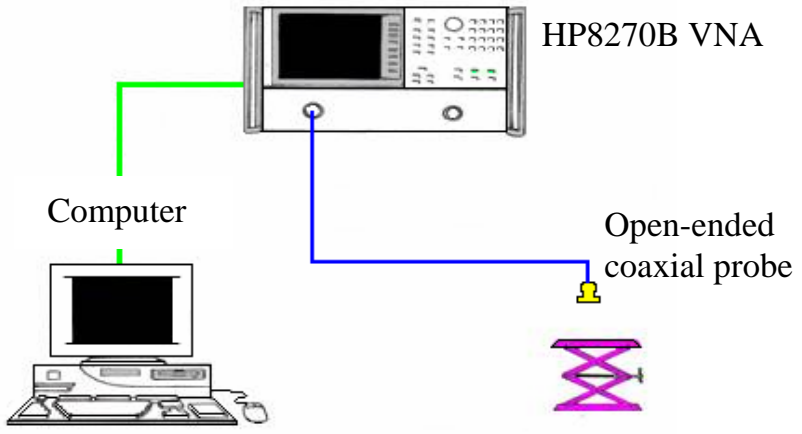

Fig.3 Experimental set-up

\section{Sample preparation}

Twenty bunches of tenera variety from different oil palms (b) were selected from the university farm for this study. The surface of the fruit was wiped dry to free excess surface moisture. Part of the fresh mesocarp of each fruit was sliced in the longitudinal direction to ensure good contact between the surface of the mesocarp and the open-ended coaxial probe as illustrated in Fig.4.

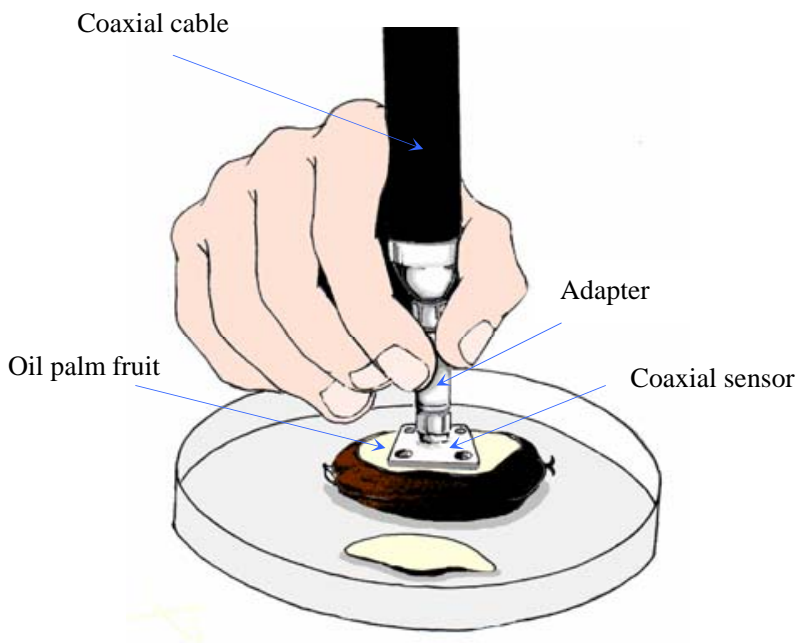

to $7.45 \mathrm{~mm}$. (b) Error network calibration. (c) Alternative transmission line calibration.

(c)

Fig.4 Part of the experimental set-up 


\section{E. Moisture content m.c measurements}

The actual moisture content of the fruit sample was determined by PORIM test method or standard oven drying method [7]. Before drying, the single fruit sample was weighted by digital scale and the value was recorded. Next, the fruit sample was dried at $(103 \pm 2){ }^{\circ} \mathrm{C}$ in the oven for two to three days. During the drying time, the fruit was taken out and cooled off, then re-weighed once every day to ensure the weight of the fruit reached a constant level. The relative moisture content m.c of oil palm fruit, in percentage (wet basis), was calculated from:

$$
\% m . c=\frac{m_{\text {Before_Dry }}-m_{\text {After_Dry }}}{m_{\text {Before_Dry }}} \times 100 \%
$$

where $m_{\text {Before_Dry }}$ and $m_{\text {After_Dry }}$ are the weight of fruit sample before and after drying in the oven, respectively. It is important to emphasize that the weight of the fruit nut is accounted for in the calculation.

\section{Relative Permittivity Calculation}

In this study, the measured reflection coefficient $\Gamma_{\text {Actual }}$ of oil palm mesocarp was converted to relative permittivity $\varepsilon_{r}$ via [8]:

$$
\varepsilon_{r}=\frac{Y_{o}}{j \omega C_{T}}\left(\frac{1-\Gamma_{\text {Actual }}}{1+\Gamma_{\text {Actual }}}\right)
$$

where $\omega$ is the angular frequency. The $Y_{o}$ and $C_{T}$ are the characteristic admittance and the total aperture capacitance of the coaxial sensor, respectively. The characteristic admittance $Y_{o}$ is expressed as:

$$
Y_{o}=\frac{2 \pi \sqrt{\varepsilon_{o} \varepsilon_{c}}}{\sqrt{\mu_{o}} \ln (b / a)}
$$

where $\varepsilon_{o}$ and $\mu_{o}$ are the free space permittivity and permeability, respectively. $\varepsilon_{c}$ is the dielectric constant of the Teflon filling the coaxial line. The $a$ and $b$ are the inner and outer radius of the coaxial conductors, respectively. The total capacitance $C_{T}$ is calculated from [9]:

$$
C_{T}=2.38 \varepsilon_{o} \varepsilon_{r}(b-a)
$$

For this design sensor, the values of $Y_{o}$ and $C_{T}$ are equal to $0.0203 \mathrm{~S}$ and $0.03 \mathrm{pF}$.

\section{RESULTS AND DISCUSSION}

The measurement results were presented in terms of reflection coefficient $\Gamma$ and the comparison with the analytical [19] and numerical calculations was carried out. Subsequently, the estimation of complex relative permittivity $\varepsilon_{r}$ of the oil palm mesocarp based on measured reflection coefficient $\Gamma_{\text {Actual }}$ was calculated using (3).

\section{A. Calibration at the aperture of the coaxial sensor}

The conventional one-port calibration normally involves measuring an open, a short and a reference material (water) of which the properties are known. The calibration procedures are implemented using the basic error-correction method as is shown in Fig.2(b) [10]. However, we have learned that the measuring of standard short is quite difficult to determine accurately and precisely, since it depends on how dense the coaxial probe is pressed to a metal material. In addition, a small air gap between aperture probe and metal material will cause significant measuring errors. To solve this problem, a perfect standard of short calibration must be designed to suite the probe which is used. Even if the perfect short standard has been designed, the calibration using the basic error-correction method gives more repeatable and precise measurement results than the transmission method, which only inputs the physical length of the probe. Nevertheless, by using the transmission line approach, the cost and measuring time will be reduced. In addition, the measurement uncertainties will not contribute to the calibration procedures, since the calibration transmission model [Eq (1)] is based on the theoretical principle.

\section{B. Significant sensing area of the coaxial sensor}

The significant sample thickness is estimated based on distance $d$ at which the measured reflection coefficient $\Gamma_{\text {Actual }}$ becomes constant when the metallic plate is moved away from the probe surface in a sample as shown in Fig.5. Fig.6 shows that when the sample thickness exceeds $3.5 \mathrm{~mm}$, the measured magnitude and phase of reflection coefficient $\Gamma$ at $4 \mathrm{GHz}$ remains unchanged for half-infinite free space and water, respectively. It can be concluded that the minimum significant thickness of sample under test is assumed to be $3.5 \mathrm{~mm}$ for this study probe below $4 \mathrm{GHz}$. 


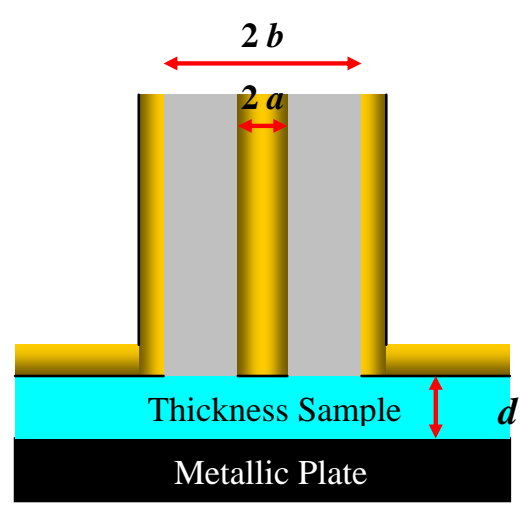

Fig.5 Finite thickness sample, $d$ backed by metallic plate
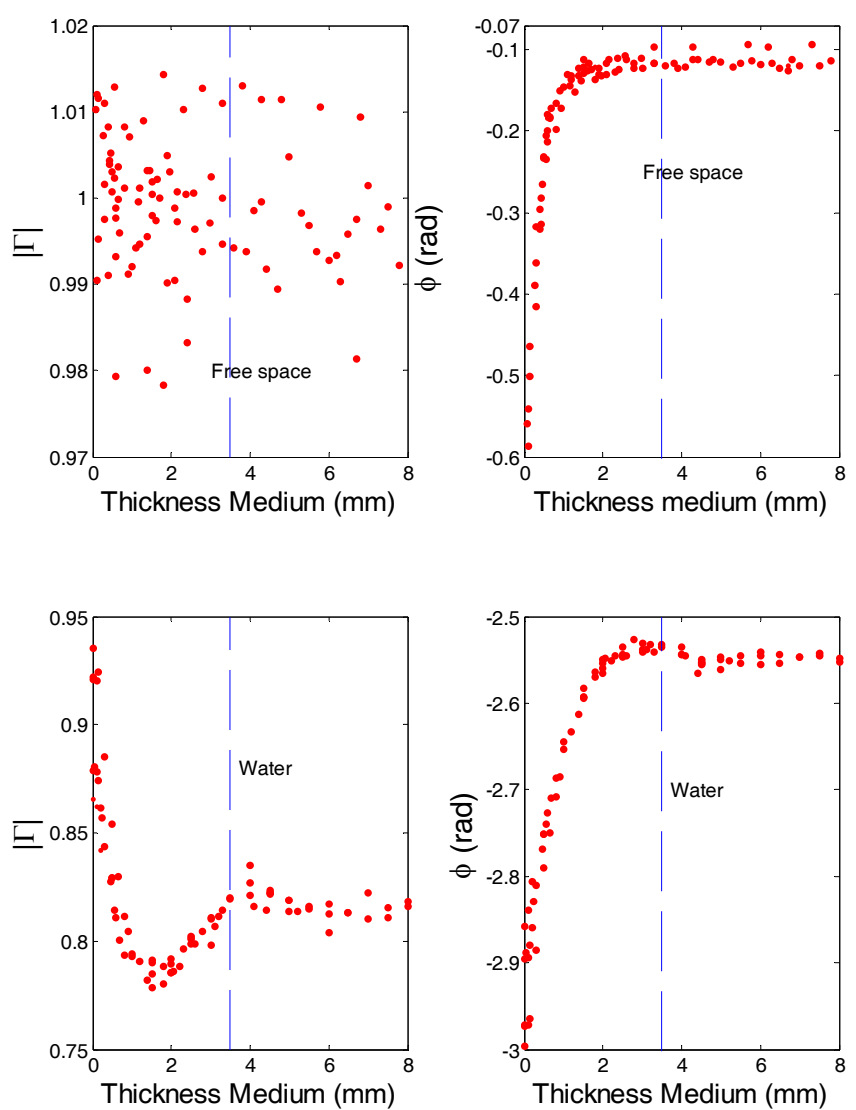

Fig.6 Variation in magnitude and phase of reflection coefficient $\Gamma$ with medium thickness (free space and water) for $4 \mathrm{GHz}$

\section{Variation in reflection coefficient $\Gamma$ with frequency for different moisture content m.c}

The variations in magnitude $|\Gamma|$ and phase $\phi$ of the reflection coefficient with moisture content $m . c$ for different frequencies were shown in Fig.7 and Fig.8, respectively. The measured magnitude $|\Gamma|$ and phase $\phi$ were in good agreement with Finite Element (FEM) simulation and analytical calculation results. The relative complex permittivity $\varepsilon_{r}$ of the oil palm mesocarp, used in simulations and calculation, was obtained from measurements using commercial HP 85070B probe. The figures suggested that $\phi$ vary linearly with the amount of moisture content m.c in the oil palm mesocarp, but not $|\Gamma|$, since $|\Gamma|$ illustrates a quadratic plotted shape with respect to moisture content $m . c$ at frequency up to $3 \mathrm{GHz}$. Besides, the measured data of $|\Gamma|$ were less precise than phase $\phi$. It was also observed that the data for $|\Gamma|$ was less sensitive to moisture content up to $4 \mathrm{GHz}$. Obviously, magnitude of reflection coefficient $|\Gamma|$ was less suitable in monitoring the fruit ripeness based on bandwidth measurements. In contrast, the sensitivity in $\phi$ with respect to moisture content $m . c$ is quite constant for all frequencies. Therefore, it was suggested that the phase of reflection coefficient $\phi$ was the most flexible parameter to relate the moisture content m.c of mesocarp. Finally, the empirical formulation of moisture content $m . c$ as a function of phase reflection coefficient $\phi$ was created by using Gaussian Elimination Method as:

$\% m . c=\left\{\begin{array}{l}\left(1.6251 f^{4}-14.6265 f^{3}+40.672 f^{2}-25.4363 f-53.4792\right) \phi+ \\ \left(-0.0564 f^{3}+0.5604 f^{2}-5.3215 f+33.377\right)\end{array}\right\}$

where $\phi$ and $f$ are the phase refection coefficient (in rad) and operating frequency (in $\mathrm{Hz}$ ), respectively.

D. Variation in relative complex permittivity, $\varepsilon_{r}$ with frequency for different moisture content m.c of oil palm mesocarp

The relationship between both dielectric constant $\varepsilon_{r}^{\prime}$ and loss factor $\varepsilon_{r}^{\prime \prime}$ of oil palm mesocarp and frequency ( $1 \mathrm{GHz}$ to $5 \mathrm{GHz}$ ) for various percentages of water content $m . c$ was shown in Fig.9 and Fig.10. The dielectric constant $\varepsilon_{r}^{\prime}$ is calculated from measured reflection coefficient $\Gamma_{\text {Actual }}$ using (3), as well as the comparison of the measurements using commercial HP85070B coaxial probe. Fig.9 revealed that the predicted and measured dielectric constant $\varepsilon_{r}^{\prime}$ overall decreased with the increase in frequency. 

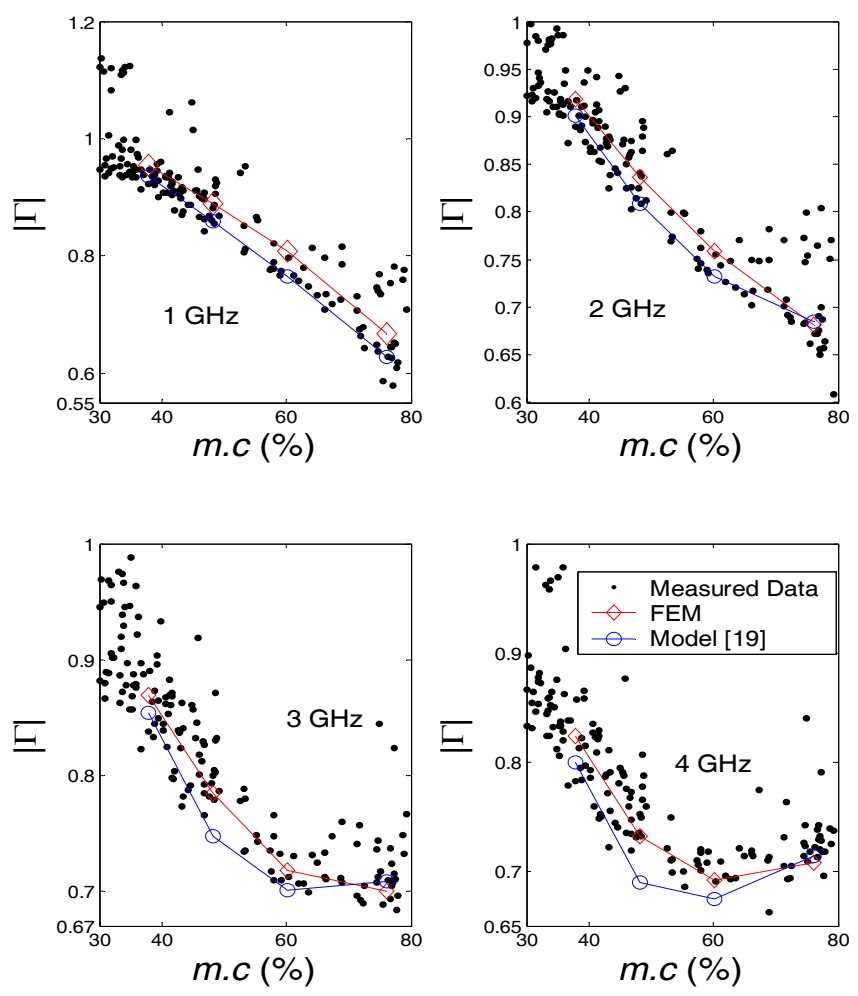

Fig.7 Variation in reflection coefficient magnitude, $|\Gamma|$ with percentage moisture content $m . c$
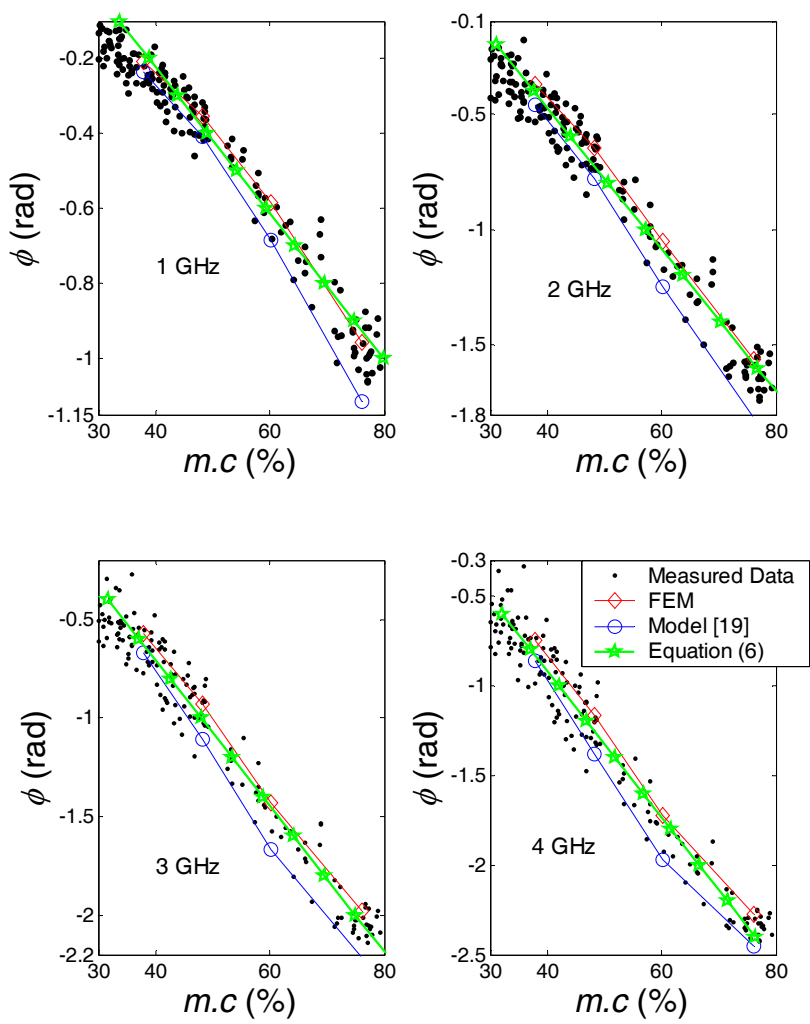

Fig.8 Variation in phase shift $\phi$ with percentage moisture content $m . c$
In all measured fruits, the loss factor $\varepsilon_{r}^{\prime \prime}$ decreased at low frequency, reached a broad minimum between 1 and $3 \mathrm{GHz}$, then increased again as shown in Fig.10. This behavior is influenced by ionic conductivity at lower frequencies, since dielectric properties in agriculture are believed to be primary dependant on water activity and ionic conductivity of fluids contained in their cellular structure. Overall, the estimated relative permittivity $\varepsilon_{r}$ of oil palm mesocarp using (3) corresponded well with measurements using commercial HP85070B coaxial probe. Based on this study, the relationship between dielectric constant $\varepsilon_{r}^{\prime}$ and percentage of moisture content in mesocarp, for example at $3 \mathrm{GHz}$, is obtained and listed in Tab.2. The decrease in relative dielectric constant $\varepsilon_{r}^{\prime}$ of the oil palm mesocarp is presumably caused by the displacement of water by oil and fibers contents. The water content m.c. is the main contributor to the value of the dielectric constant of the oil palm mesocarp, since the dielectric constant of water ( $\varepsilon_{r}^{\prime}=80$ at DC) is far greater than that of other substances in the oil palm mesocarp (such as oil and fiber). In addition, the orientation of water molecules is sensitive to the microwave frequencies, especially at 2.45 GHz.

Table 2 Relationship between \% water content $m . c$ and dielectric constant $\varepsilon_{r}^{\prime}$ of oil palm mesocarp for $3 \mathrm{GHz}$ at $(25 \pm 1)^{\circ} \mathrm{C}$

\begin{tabular}{c|c}
\hline $\begin{array}{c}\text { Water Content, } \\
\text { m.c (\%) }\end{array}$ & $\begin{array}{c}\text { Dielectric } \\
\text { Constant, } \varepsilon_{r}^{\prime}\end{array}$ \\
\hline $30-40$ & $10-15$ \\
$40-50$ & $15-25$ \\
$50-60$ & $25-35$ \\
$60-70$ & $35-52$ \\
$70-80$ & $52-62$ \\
\hline
\end{tabular}

In this work, the relative permittivity $\varepsilon_{r}$ of oil palm mesocarp, ranging from $30 \%$ to $80 \%$ of water content at (25 $\pm 1{ }^{\circ} \mathrm{C}$ ), can be represented by a sum of the two relaxation processes dielectric model as:

$$
\varepsilon_{r}=\varepsilon_{\infty}+\frac{\varepsilon_{s}-\varepsilon_{1}}{\left[1+\left(j \omega a_{1} \tau_{1}\right)^{a_{2}}\right]^{a_{3}}}+\frac{\varepsilon_{1}-\varepsilon_{\infty}}{1+\left(j \omega \tau_{2}\right)^{a_{4}}}-\frac{j \sigma}{\omega \varepsilon_{o}}
$$

where $\tau_{1}$ and $\tau_{2}$ are the relaxation time for low and high- 
frequency processes, respectively. The $\varepsilon_{s}$ and $\varepsilon_{1}$ are the static permittivity for first and second relaxation processes, as well as $\varepsilon_{\infty}$ is the optical permittivity. The $\omega$ is the angular frequency and $\sigma$ is the conductivity of oil palm mesocarp at lower frequencies. The $a_{1}, a_{2}, a_{3}$ and $a_{4}$ are the empirical constants, which are determined by optimized, up to 120 set measured data using commercial HP85070B probe. The parameters in (7) as a function of water content $m . c$ (\%) are listed in Appendix. Equation (7) is quite in agreement with random selected measured data using the study coaxial probe. At moisture above $70 \%$, the higher measurement uncertainty appeared due to the water accumulated at the surface between the sensor and the fruit when the sensor is pressed firmly to the sample fruits.

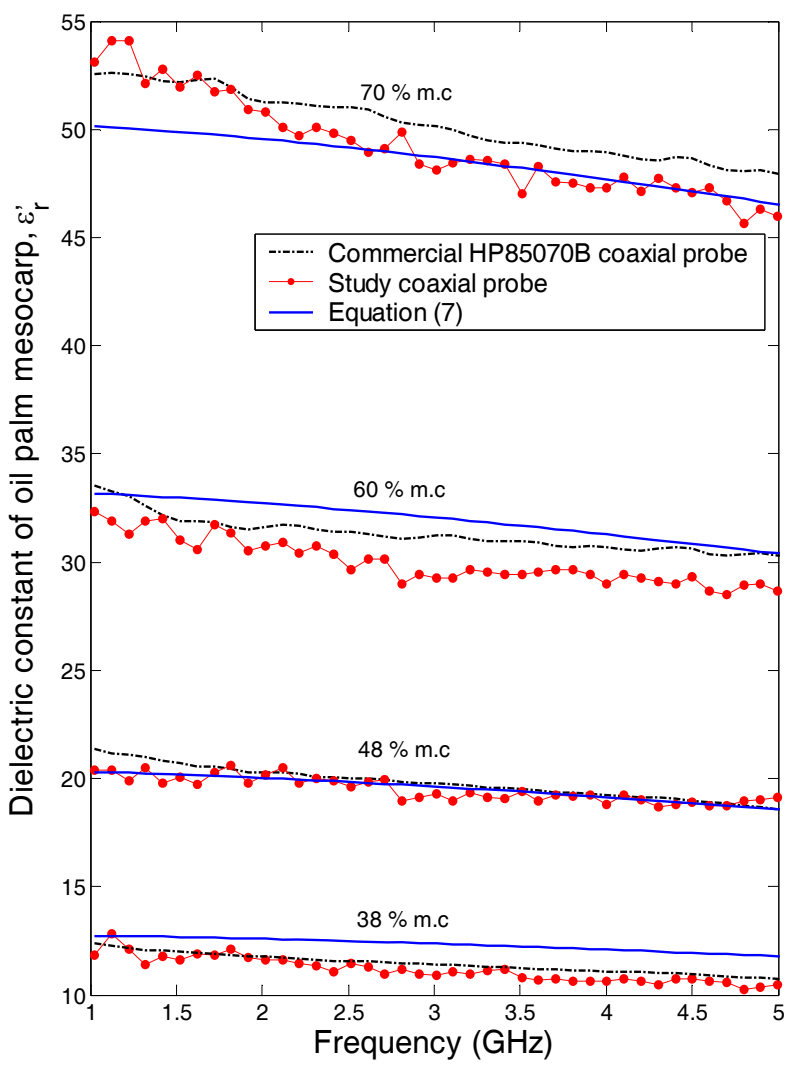

Fig.9 The variations in dielectric constant, $\varepsilon_{r}^{\prime}$ of oil palm mesocarp with frequency for various \% moisture content at ( $25 \pm 1)^{\circ} \mathrm{C}$

\section{CONCLUSION}

For this study, the coaxial sensor is suitable to determine the fruit quality based on measured phase of the reflection coefficient $\phi$ alone for medium fruit up to $5 \mathrm{GHz}$. The estimated relative permittivity $\varepsilon_{r}$ of oil palm mesocarp from directly inverse solutions corresponded well with measurements using commercial HP85070B coaxial probe. The microwave sensor can be also applied to other fields such as soil moisture determination and quality control of latex.

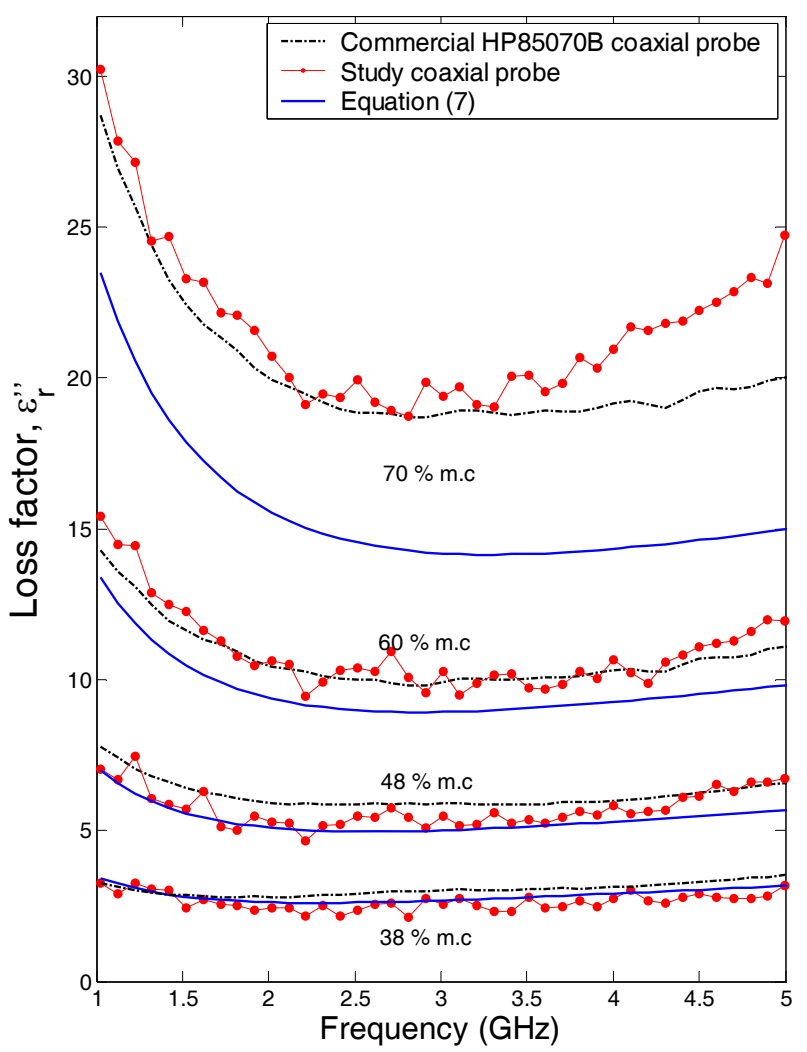

Fig.10 The variations in loss factor $\varepsilon_{r}^{\prime \prime}$ of oil palm mesocarp with frequency for various \% moisture content at ( $25 \pm 1)^{\circ} \mathrm{C}$

\section{APPENDIX}

The parameters in (7) as a function of water content m.c (\%) are listed below:

$$
\varepsilon_{s}=\left[\begin{array}{l}
-3.9899 \times 10^{-4}(m . c)^{3}+8.0046 \times 10^{-2}(m . c)^{2} \\
-3.8988(m . c)+67.258
\end{array}\right] \pm 0.9792
$$

$$
\varepsilon_{1}=\left[\begin{array}{l}
-1.8394 \times 10^{-5}(m . c)^{4}+3.8076 \times 10^{--3}(\text { m.c })^{3} \\
-0.27371(\text { m.c })^{2}+8.7394(\text { m.c })-98.783
\end{array}\right] \pm 0.5093
$$

$\varepsilon_{\infty}=v_{\text {water }} \varepsilon_{\infty}^{\text {Water }}+\left(0.84-v_{\text {water }}\right) \varepsilon_{\infty}^{\text {Oil }}+0.16 \varepsilon_{\infty}^{\text {Fiber }}$ 


$$
v_{\text {water }}=\frac{0.01 m . c\left(0.16 \rho_{\text {Fiber }}-0.16 \rho_{\text {Oil }}+\rho_{\text {Oil }}\right)}{\rho_{\text {Water }}-0.01 \rho_{\text {Water }}+0.01 \rho_{\text {Oil }}}
$$

where $\quad \varepsilon_{\infty}^{\text {Water }}=4.9, \quad \varepsilon_{\infty}^{\text {Oil }}=2.5, \quad \varepsilon_{\infty}^{\text {Fiber }}=2.2, \quad \omega=2 \pi f$ $\rho_{\text {water }}=0.9959 \mathrm{gml}^{-1}, \quad \rho_{\text {Oil }}=0.9073 \mathrm{gml}^{-1}$ and $\rho_{\text {Fiber }}=0.9200 \mathrm{gcm}^{-3}$

$$
\begin{array}{r}
\sigma=6.2861 \times 10^{-4}(m . c)^{2}-3.6521 \times 10^{-2}(\text { m.c })+6.3931 \times 10^{-1} \\
\pm 0.02482 \Omega^{-1} \mathrm{~m}^{-1}
\end{array}
$$$$
a_{1}=-2.2890 \times 10^{-4}(m . c)^{2}+3.6771 \times 10^{-2}(m . c)+1.4734 \times 10^{-1}
$$$$
\pm 0.0008234
$$$$
a_{2}=-3.5634 \times 10^{-6}(\text { m.c })^{2}-4.5790 \times 10^{-4}(\text { m.c })+1.0124
$$$$
\pm 0.00002904
$$

$$
a_{3}=4.0888 \times 10^{-5}(\text { m.c })^{2}-8.7443 \times 10^{-3}(\text { m.c })+1.1543
$$$$
\pm 0.0008381
$$

$$
a_{4}=3.5374 \times 10^{-5}(\text { m.c })^{2}-2.5052 \times 10^{-3}(\text { m.c })+8.7535 \times 10^{-1}
$$$$
\pm 0.004263
$$

\section{ACKNOWLEDGMENT}

This work was supported in part by the Ministry of Science, and Environment of Malaysia under project IRPA 09-02-04-0460-EA001.

\section{REFERENCES}

[1] Ariffin, A., Mat, S.R., Banjari, M., Wan, O.W.E. (1990). Morphological changes of the cellular component of the developing palm fruit (Terera: Elaeis guineensis). Palm Oil Research Institute of Malaysia Bulletin, 21, 30-34.

[2] Siregar, I.M. (1976). Assessment of ripeness and crop control in oil palm. In Wastie, R.L., Earps, D.A. (eds.) Proc. of Malaysian Int. Aqric. Oil Palm Conf. (Incorporated Society of Planters). Kuala Lumpur: PORIM, 711-723.

[3] Southworth, A. (1976). Oil palm harvesting - a practical approach to the optimization of oil quantity and quality. In Wastie, R.L., Earps, D.A. (eds.) Proc. of Malaysian Int. Aqric. Oil Palm Conf. (Incorporated Society of Planters). Kuala Lumpur: PORIM, 721-740.
[4] Kaatze, U. (2005). Electromagnetic Aquametry (ed. K. Kupfer). New York: Springer.

[5] Marcuvitz, N. (1964). Waveguide Handbook. Boston: Boston Technical Publishers.

[6] Nyfors, E., Vainikainen, P. (1989). Industrial Microwave Sensors. Norwood, MA: Artech House, Inc.

[7] Siew, W.L., Tang, T.S., Tan, T.A. (1995). PORIM Test Methods. Bangi: Palm Oil Research Institute of Malaysia.

[8] Stuchly, M.A., Atley, T.W., Samaras, G.M., Taylor, G.E. (1982). Measurement of radio frequency permittivity of biological tissues with an open-ended coaxial line: Part II - experimental results. IEEE Trans. Microwave Theory Tech., 30, 87-91.

[9] Gajda, G.B., Stuchly, S.S. (1983). Numerical analysis of open-ended coaxial lines. IEEE Trans. Microwave Theory Tech., 31, 380-384.

[10] Kraszewski, A., Stuchly, M.A., Stuchly, S.S. (1983). ANA calibration method for measurements of dielectric properties. IEEE Trans. Instrum. Meas., 32, 385-386.

[11] Hartley, C.W.S. (1977). The Oil Palm. London: Longman Group Limited.

[12] Abbas, Z. (1994). A Microstrip Sensor for Determination of Harvesting Time for Oil Palm Fruits. MSc Thesis, Universiti Putra Malaysia.

[13] Teoh, L.H. (1997). Development of Conductor-Backed Coplanar Waveguide Moisture Sensor. MSc Thesis, Universiti Putra Malaysia.

[14] Zakaria, Z. (1998). Dielectric Properties of Oil Palm Mesocarp at Various Moisture Content. MSc Thesis, Universiti Putra Malaysia.

[15] Mokhtar, R. (2004). RDWG Technique for Determination of Complex Permittivity and Moisture Content of Oil Palm Fruits. MSc Thesis, Universiti Putra Malaysia.

[16] Lee, K.Y. (2004). Development of a $500 \mathrm{MHz}$ Reflectometer using Stripline Coupler for Moisture Measurement of Oil Palm Fruits. MSc Thesis, Universiti Putra Malaysia.

[17] Ali, A. (2007). A Study on Relationship between Reflection Coefficient and Moisture Content in Oil Palm Fruits using Rectangular Waveguide. MSc Thesis, Universiti Putra Malaysia.

[18] You, K.Y. (2006). Application of Open-Ended Coaxial Sensor to Determine Oil Palm Fruit Ripeness. Ph.D Thesis, Universiti Putra Malaysia.

[19] Marcuvitz, N. (1964). Waveguide Handbook. Boston: Boston Technical Publishers. 